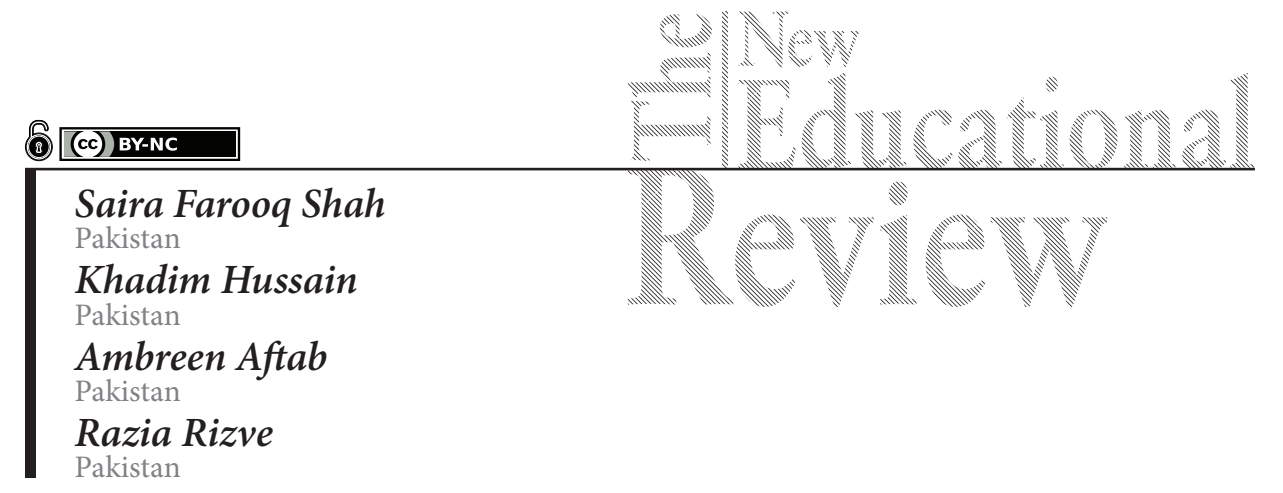

\title{
Social Media Usage and Students' Psychological Well-being: An Empirical Analysis of District Mirpur, AJ\&K, Pakistan
}

DOI: 10.15804/tner.2021.64.2.05

\begin{abstract}
The rapid inventions of social media in current era have changed the wellbeing of human lives. The current study aimed to explore the correlation between social media usage and undergraduate students' psychological wellbeing in Mirpur, Azad Jammu and Kashmir. Two research instruments were used in this study Social Media Addiction Scale-Student Form (SMAS-SF) and Flourishing Scale (FS). The first scale measures the usage capacity of social media and the second measures the psychological wellbeing of undergraduate students. The correlation between the scores obtained from the scales was determined by applying Pearson correlation formula. The positive correlation between social media usage and psychological wellbeing of undergraduate students has been found in this study. The other finding related to most preferred social media concluded that WhatsApp was most preferable social media among undergraduate students. $61 \%$ undergraduate students used the WhatsApp to engage their daily life in using social media.
\end{abstract}

Keywords: social media, psychological wellbeing, undergraduate students 


\section{Introduction}

Social media is a new invention in modern era. People interact with each other via different networking sites and share their information around the world. This distinctive development endows individual to become nearer to others and interconnect virtually and share information promptly. People share their information, videos, pictures, announcements, update their profile, get comments, and engage their lives.

According to Livingstone (2005) the rate of social media usage is higher among the youth. By feeling happy, building healthy relationship with their fellows and family, social media have become person's good wellbeing. Wellbeing is a state of person in which they feel happy, live a satisfactory life, have positive relation with others (Ryan and Deci, 2001).

Humans are basically socially connective species; they want to live in a group with great social interactions because it is human need to share and elaborate their feeling for improving their wellbeing. If the interaction among people is strong, it creates a strong satisfaction in their lives (Leary, et al., 1995). While addressing it, Festinger (1954) proposed the social comparison theory which explains the nature of human beings who behave and compare themselves with others in aspect of upward and downward social comparison theory.

People compare themselves with others to improve their attitude and living style with the use of social media. People compare themselves in aspect of their attitude, capabilities, and values with others to improve their attitude, capabilities, and values (Festinger, 1954). The social media and the new technologies change the aspect of every person's life and make them digital. Majority of world's population of various age groups are frequently using different social media sites for communication and entertainment. This communication has connection with wellbeing of people as well.

There is no doubt that these social media technologies have developed a wide range of activities for users by developing substantial online learning procedures. These technologies also increase the inter and intra relation, indulgence and response between the students, friends, and teachers too. But the social technology has positive and negative influence on psychological well-being of the students at variant age levels. Therefore, the current study aimed to explore the influence of social technology on the undergraduate students and the relationship between them at District Mirpur of Azad Jammu and Kashmir. 


\section{Objective:}

To investigate the relationship between the social media usage and the psychological wellbeing of undergraduate students in District Mirpur, Azad Jammu and Kashmir.

To achieve the objective of the study a hypothesis has been formulated.

\section{Hypothesis:}

There is no significant relationship between the use of social media and the psychological wellbeing of undergraduate students in Mirpur, Azad Jammu and Kashmir.

The study has been limited to only eight main social networking sites. Moreover, the study is limited to the psychological wellbeing of the undergraduate students.

\section{Literature Review}

Shirase (2012) found that across the world approximately 1.5 billion people have their own social networking profile which has increased over the years. Facebook is the predominantly used social media to share comments, information, videos, audios, pictures, and images (Sheldon \& Bryant, 2016). Whereas, Twitter belongs to microblog social media in which people tweet with others to share the information and happenings around them. YouTube is also a very popular social media site that provides information in the form of videos. Every day even every second there is billion users who make use of this social media. Instagram and Snapchat both are mobile-based social media (Stec, 2015).

Psychological wellbeing is about having a positive mental states, such as happiness or satisfaction (Edward, 2005). People having less depression, anxiety, fear and free of boredom develop positive mental health. Hence, psychological wellbeing contributes to the positive relation with others (Keyes \& Haidt, 2003). Deci \& Ryan (2008) distinguished two main approaches. Hedonic (Positive relation with other individuals) and Eudaimonia (Self-acceptance). Human flourishing is the basic condition and process of being positive, psychologically healthy human being. It is a positive attitude of human being that describes human health (Gable \& Haidt, 2005). Seligman (2011) identified positive emotion, engagement, relationships, meaning and achievement that increase human tendency to achieve positive psychological wellbeing.

Shaheen (2008) stated that the use of social media among students provides a larger platform for expressing their feeling about their rights, encouraging their 
confidence and enhancing their awareness. At the time of critical situation, the use of social media among students provides an opportunity to release tension by sharing their thoughts with others and getting suggestions from others how to escape from the situation.

Mcdool, et al (2016) discovered that the use of social technology affected students' well-being negatively. The social media users were found less satisfied with their lives and studies except their relationships. Further it was highlighted that the girls were suffering more than boys. Khurshid \& Haroon (2018) concluded that social media have great influence on students' lives and enhance their information that help them in their academic activities. Social media have a direct relationship with the human psychological well-being especially for young people like university students.

Alkan \& Doğan (2018) explored that there was no significant relationship between social media usage and the wellbeing of secondary school students because the secondary school students do not use social media a lot and their wellbeing doesn't increase by the use of social media. Further there was no difference in results while comparing usage of social media among genders.

Dhir, et al (2018) discovered that compulsive social media usage leads students towards social media fatigue which in turn causes higher level of anxiety and depression in them. The social media indirectly affect their wellbeing and cause fear of missing out and fatigue. Weinstein (2018) found that there are multiple dimensions of social media usage and well-being. Sometimes it had positive influence and sometimes it had negative influence. Therefore, this is a kind of emotional seesaw that has different effects on different people living in different settings.

Vannucci \& Ohannessian (2019) explained that the higher use of social technology had variant effects on psychological wellbeing of early adolescence whereas lower use of technology had different effects. They concluded that the additional use of social technology was problematic for the children between age 11-14. Symptoms of higher-level depression, anxiety, irresponsible behaviors, family disagreements and less family and friend support had been observed in adolescents. Whereas the adolescents who were in low social technology usage subgroup had fewer or no evidence of such psychological issues.

Tariq, et al. (2019) analyzed the effects of smartphone usage on the psychological wellbeing of school going children in Lahore, Pakistan and discovered that longterm smartphone usage was significantly associated with behavioral problems as well as psychological problems and the smart phones have made access to the social media world even more easy. 


\section{Material and Methods}

The current study is quantitative in nature and correlational design has been employed to explain the relationship between usage of social media and undergraduate students' psychological wellbeing. Pearson correlation formula (Creswell, 2014) has been used to find out relationship between usage of social media and psychological wellbeing of undergraduate students. High scores indicate the high level of relationship between both variables.

\section{Population}

The population of this study is based on undergraduate students of Mirpur, Azad Jammu and Kashmir. There were thirteen governmental institutions in which four colleges are for boys and seven are for girls, one is co-education, and one university. The total number of undergraduate students is mentioned below:

Table 1. Number of Undergraduate Students in Mirpur, Azad Jammu and Kashmir

\begin{tabular}{lc}
\hline \multicolumn{1}{c}{ Students in degree classes in colleges } & 3236 \\
\hline Students in BS classes in colleges & 459 \\
\hline Students in university & 4253 \\
\hline Grand Total & 7948 \\
\hline
\end{tabular}

\section{Sample}

The sample of this study has been composed of one thousand undergraduate students (five hundred males and five hundred female) from different government institutions by applying random sampling technique.

\section{Data Collection Tool}

This study was based on two research instruments that are

- Social Media Addiction Scale-Student Form (SMAS-SF) measured the social media usage score of undergraduate students.

- Flourishing Scale (FS) measured the score of psychological wellbeing of undergraduate students.

\section{Social Media Addiction Scale-Student Form (SMAS-SF):}

Sahin (2018) elaborated this scale as an instrument to measure the use and addiction of social networking sites among students. The scale, in its original form, consisted of 29 items with Likert construction and five response options, ranging 
from "strongly agree" to "strongly disagree". Furthermore, Sahin (2018) tried to make this scale more reliable and valid instrument. The overall reliability of this scale is $\mathrm{r}=.94$, Spearman Brown reliability coefficient (.91), Guttman Split-Half (.90) and Cronbach Alpha reliability coefficient (.93), all these findings showed the internal validity and reliability of the whole scale. It consists of four factors a) Virtual Tolerance, b) Virtual Communication, c) Virtual Problem, and d) Virtual Information. These four factors are investigated by 29 items. All items of this scale are positive in nature, describe positive attitude of students toward social media usage.

\section{Flourishing Scale (FS):}

Diener, et al. (2010) attempted to create more reliable and valid instrument to measure the students' psychological wellbeing. This instrument was developed to examine the insufficient measuring scores about the psychological wellbeing. It consists of eight items; all items describe the positive direction of human psychological wellbeing. High score of this scale represents the positive and high relation of human being. The internal consistency of this scale was .83, and factor loading ranged from .60 to .78 , and item total correlation ranged from .47 to .67 represent the high validity and reliability of this scale.

\section{Pilot Testing of the Scales:}

The reliability and validity of each scale was already established but we do further pilot testing to content reliability of both scales. One hundred and ninety intermediate students were selected for pilot testing. Ninety male students from Post Graduate College for Boys and ninety female students from Ghazi-ElahiBakhsh Government Degree College for Women, Mirpur, Azad Jammu and Kashmir. The reliability of both scales is mentioned in below table.

Table 2. Reliability of Both Scales

\begin{tabular}{ll}
\hline \multicolumn{1}{c}{ Scale } & Cronbach's Alpha Reliability \\
\hline SMAS-SF & \multicolumn{1}{c}{.64} \\
\hline Virtual Tolerance & .78 \\
\hline Virtual Communication & .79 \\
\hline Virtual Problem & .76 \\
\hline Virtual Information & .86 \\
\hline Overall SMAS-SF reliability & .74 \\
\hline Overall FS reliability &
\end{tabular}


The overall reliability of both scales is excellent for conducting and applying a research tool for research study. The Cronbach' Alpha value $\alpha=.86$ and $\alpha=.74$ of both SMAS-SF and FS respectively shows good level of reliability of scales (Bryman and Bell, 2007).

\section{Results and Discussion}

The collected data studied by applying Statistical Package for Social Sciences (SPSS) and Microsoft Excel. Both descriptive as well as inferential data analysis have been done.

\section{Descriptive Data Analysis}

Descriptive data analysis composed of demographic information of undergraduate students as representing students' level of education, their age, and their perception about most preferred social media.

Table 3. Level of education and age of undergraduate students in term of percentage and frequency

\begin{tabular}{llllcc}
\hline Education level & Percentage & Frequency & Age & Percentage & Frequency \\
\hline B.A/BSc/B.Com/B.S.Ed. & 64.1 & 641 & $17-21$ years & 87.9 & 879 \\
\hline BS/BBF & 24.0 & 240 & 22-25years & 10.8 & 108 \\
\hline B.Ed./ B.Ed. Hons & 3.5 & 35 & 26-29years & 0.7 & 7 \\
\hline M.A/M.Sc./M.Ed. & 8.4 & 84 & Above 29years & 0.6 & 6 \\
\hline
\end{tabular}

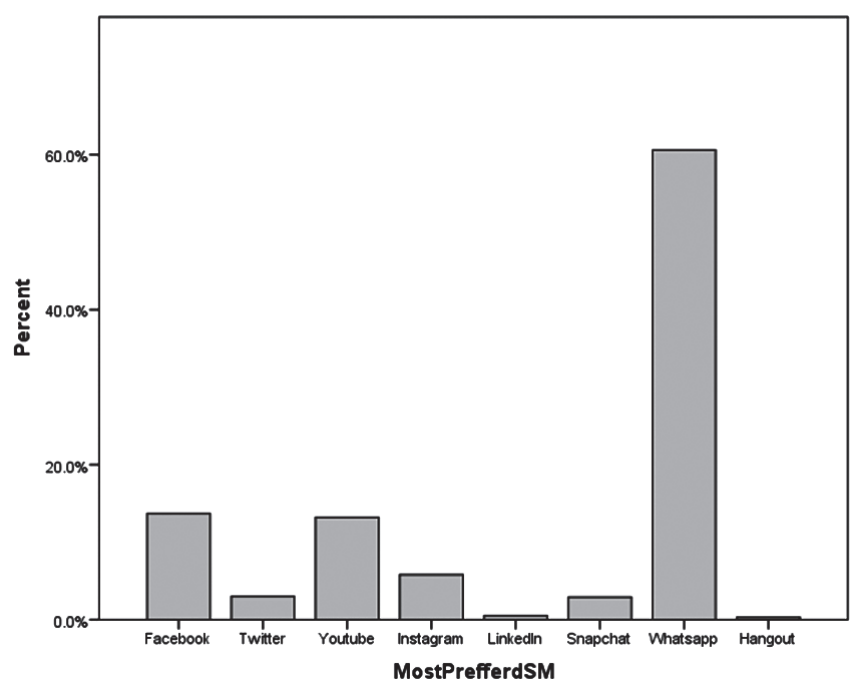

Figure 1.

Most preferred Social media websites among undergraduate students 
Most respondents belong to undergraduates of age group 17-21 years. The high percentage and frequency of this age group showed that very young age students fall in using social media and evaluate their psychological wellbeing.

The Figure 1 revealed that WhatsApp was most preferable social media among undergraduate students with high percentage and Hangout and LinkedIn were the least preferable social networking sites among undergraduate students of Mirpur, Azad Jammu and Kashmir

\section{Inferential Data Analysis}

In inferential data analysis, the Pearson correlation formula was employed to evaluate the relationship between both scales. Pearson correlation used to measure the relationship between the usage of social media and the psychological wellbeing of undergraduate students. Both scales were introduced in measuring the relationship in factor wise categories.

\section{Factor 1 (Virtual Tolerance)}

Item 1-5 of the questionnaire ask about the virtual tolerance of the social media users and the results after applying statistical formula are shown in the following table.

Table 4. Correlation matrix of SMAS-SF (Virtual Tolerance) with total item wise of FS

\begin{tabular}{llll}
\hline & & \multicolumn{1}{c}{$\begin{array}{c}\text { Virtual Toler- } \\
\text { ance value }\end{array}$} & \multicolumn{1}{c}{$\begin{array}{c}\text { Flourishing Scale } \\
\text { Value }\end{array}$} \\
\hline Virtual Tolerance value & $\begin{array}{l}\text { Pearson } \\
\text { Correlation }\end{array}$ & 1 & $.251^{\star *}$ \\
\cline { 2 - 4 } & $\begin{array}{l}\text { Sig. } \\
(2 \text {-tailed })\end{array}$ & .000 \\
\cline { 2 - 4 } & $\mathrm{N}$ & 1000 & 1000 \\
\hline Flourishing Scale Value & $\begin{array}{l}\text { Pearson } \\
\text { Correlation }\end{array}$ & $.251^{\star *}$ & 1 \\
\cline { 2 - 4 } & $\begin{array}{l}\text { Sig. } \\
(2 \text {-tailed })\end{array}$ & .000 & \\
\hline & $\mathrm{N}$ & 1000 & 1000 \\
\hline
\end{tabular}

${ }^{*}$ Correlation is significant at 0.05 level (2-tailed)

The Pearson correlation between virtual tolerance and flourishing of human being has shown that there is positive relationship between virtual tolerance and undergraduate students' psychological wellbeing with $\mathrm{r}=.251$ at significant level. 


\section{Factor 2 (Virtual Communication)}

Item 6-14 of the questionnaire show the virtual communication of undergraduate students with their family, friends, and educational circle for getting and sending information. These items have asked about the use of social media particularly for communication and the results have been displayed in the table below.

Table 5. Correlation matrix of SMAS-SF (Virtual Communication) with total item wise of FS

\begin{tabular}{llll}
\hline & & Virtual Communication & Flourishing Scale \\
\hline $\begin{array}{l}\text { Virtual Commu- } \\
\text { nication }\end{array}$ & Pearson Correlation & 1 & $.307^{\star *}$ \\
\cline { 2 - 4 } & Sig. (2-tailed) & & .000 \\
\cline { 2 - 4 } & $\mathrm{N}$ & 1000 & 1000 \\
\hline \multirow{2}{*}{ Flourishing Scale } & Pearson Correlation & $.307^{\star *}$ & 1 \\
\cline { 2 - 4 } & Sig. (2-tailed) & .000 & 1000 \\
\cline { 2 - 4 } & $\mathrm{N}$ & 1000 & \\
\hline
\end{tabular}

${ }^{* *}$ Correlation is significant at the 0.05 level (2-tailed).

The table 5 revealed that virtual communication is a great attraction among undergraduate students. The finding of Pearson correlation between virtual communication and flourishing showed strong and positive relationship with $\mathrm{r}=.307$ at significant level which means students feel good which using social media.

\section{Factor 3 (Virtual Problem)}

Item no 15-23 had shown the virtual problems related to social media. These items had inquired about the uncomfortable feeling and experiences faced by undergraduate students and the results are given in the following table.

Table 6. Correlation matrix of SMAS-SF (Virtual Problem) with total item wise of FS

\begin{tabular}{llll}
\hline & & Virtual Problem & Flourishing Scale \\
\hline $\begin{array}{l}\text { Virtual Prob- } \\
\text { lem }\end{array}$ & Pearson Correlation & 1 & $.255^{\star *}$ \\
\cline { 2 - 4 } & Sig. (2-tailed) & .000 \\
\cline { 2 - 4 } & $\mathrm{N}$ & 1000 & 1000 \\
\hline $\begin{array}{l}\text { Flourishing } \\
\text { Scale }\end{array}$ & Pearson Correlation & $.255^{\star \star}$ & 1 \\
\cline { 2 - 4 } & Sig. (2-tailed) & .000 & 1000 \\
\cline { 2 - 4 } & $\mathrm{N}$ & 1000 & \\
\hline
\end{tabular}

${ }^{*}$ Correlation is significant at the 0.01 level (2-tailed). 
Social media may create some virtual problems, but the results show that there are not many virtual problems that influence the psychological wellbeing negatively. The findings of this virtual problem show that there is a positive relationship between virtual problem and undergraduate students' psychological wellbeing.

\section{Factor 4 (Virtual Information)}

Item 24-29 inquired about the use of social networking sites for sharing and spreading information. The results of these items are shown in the following table.

Table 7. Correlation matrix of SMAS-SF (Virtual Information) with total item wise of FS

\begin{tabular}{llcc}
\hline & & Virtual Information & Flourishing Scale \\
\hline $\begin{array}{l}\text { Virtual Infor- } \\
\text { mation }\end{array}$ & $\begin{array}{l}\text { Pearson Corre- } \\
\text { lation }\end{array}$ & 1 & $.415^{\star *}$ \\
\cline { 2 - 4 } & Sig. (2-tailed) & & .000 \\
\cline { 2 - 4 } & $\mathrm{N}$ & 1000 & 1000 \\
\hline $\begin{array}{l}\text { Flourishing } \\
\text { Scale }\end{array}$ & $\begin{array}{l}\text { Pearson Corre- } \\
\text { lation }\end{array}$ & $.415^{* *}$ & 1 \\
\cline { 2 - 4 } & Sig. (2-tailed) & .000 & 1000 \\
\cline { 2 - 4 } & $\mathrm{N}$ & 1000 & \\
\hline
\end{tabular}

** Correlation is significant at the 0.05 level (2-tailed).

Social media have great impact on virtual information. Many students use the social media to get information from all over the world. The finding about virtual information and flourishing of undergraduate students revealed that there is a powerful and positive relationship between virtual information and flourishing of undergraduate students with $\mathrm{r}=.415$ at significant level.

$\mathrm{H} \circ$ : There is no significant relationship between usage of social media and undergraduate students' psychological wellbeing. 


\section{Major Analysis}

\section{Social Media Addiction Scale-Student Form and Flourishing Scale}

Table 8. Correlation matrix of SMAS-SF (Overall) with total item wise of FS

\begin{tabular}{|c|c|c|c|}
\hline & & Social Media Scale & Flourishing Scale \\
\hline \multirow{3}{*}{$\begin{array}{l}\text { Social Me- } \\
\text { dia Scale }\end{array}$} & Pearson Correlation & 1 & $.357^{\star \star}$ \\
\hline & Sig. (2-tailed) & & .000 \\
\hline & $\mathrm{N}$ & 1000 & 1000 \\
\hline \multirow{3}{*}{$\begin{array}{l}\text { Flourishing } \\
\text { Scale }\end{array}$} & Pearson Correlation & $.357^{\star *}$ & 1 \\
\hline & Sig. (2-tailed) & .000 & \\
\hline & $\mathrm{N}$ & 1000 & 1000 \\
\hline
\end{tabular}

${ }^{* *}$ Correlation is significant at the 0.05 level (2-tailed).

The overall findings about social media users and undergraduate students' psychological wellbeing have revealed that there is positive relationship between them and correlation value $\mathrm{r}=.357$ is at significant level.

\section{Conclusion}

The most preferred social media among undergraduate students is WhatsApp. The study reveals that there is a positive relationship between usage of social media and psychological wellbeing amongst undergraduate students. The moderate relationship between virtual tolerance and flourishing of undergraduate students with $\mathrm{r}=.251$ show that students have slightly positive relationship between social media use with their psychological wellbeing. There is a positive relationship between virtual communication and flourishing with Pearson value $r=.307$ at significant level.

With great use of social media students get more information and enhance their psychological wellbeing as well. This is revealed by positive relationship between virtual information and flourishing. The overall finding of the study on Social Media Addiction Scale-Student Form and Flourishing Scale revealed that there is a moderate and positive relationship between social media usage and undergraduate students' psychological wellbeing with $\mathrm{r}=.357$ at significant level. This finding has not supported the hypothesis therefore, the Null Hypothesis has been rejected. 
The use of social networking sites has become an essential part of every student's life. Students use different social media during their study and daily lives to get more and more virtual information worldwide. By engaging in their social activities, students fall in virtual world and enhance their virtual information. Many students who do not know about social media privacy may be victimized by cyber bullying, therefore it is necessary for them to know their rights.

\section{References}

Alkan, H., \& Doğan, B. (2018). A research on the relationship between high school students' social media usage and Their Wellbeing. International Journal of Educational Research Review, 3(4): 97-102.

Bryman, A., \& Bell, E. (2007). Business research strategies. United State of America: Oxford University Press.

Creswell, J.W. (2014). Research design: Qualitative, quantitative and mixed methods approaches ( $2^{\text {nd }}$ ed.). Thousand Oaks, CA: SAGE Publications

Deci, E.L., \& Ryan, R.M. (2008). Hedonia, eudaimonia, and well-being: An introduction. Journal of Happiness Studies, 9, 1-11.

Dhir, A., Yossatorn, Y., Kaur, P., \& Chen, S. (2018). Online social media fatigue and psychological wellbeing-A study of compulsive use, fear of missing out, fatigue, anxiety and depression. International Journal of Information Management, 40, 141-152.

Diener, E., Wirtz, D., Tov, W., Kim-Prieto, C., Choi, D.W., Oishi, S., \&Biswas-Diener, R. (2010). New well-being measures: Short scales to assess flourishing and positive and negative feelings. Social Indicator Research, 97, 143-156.

Digital Report (2020) accessed by https://datareportal.com/reports/digital-2020-pakistan retrieved on 1-9-2020.

Edward, K. (2005). The phenomenon of resilience in crisis care mental health clinicians. International Journal of Mental Health Nursing, 14(2): 142-148.

Festinger, L. (1954). A theory of social comparison. Human Relations 14:48-64.

Gable, S.L., \& Haidt, J. (2005). What (and why) is positive psychology? Review of General Psychology, 9(2): 103-110.

Keyes, C.L.M., \& Haidt, J. (2003). Flourishing: Positive psychology and the life well lived. Washington DC: American Psychological Association.

Khurshid, M., \& Haroon, Z. (2018). Body image, generalized contentment and psychological well-being in university students. Journal of Research and Reviews in Social Sciences Pakistan, 1(1): 71-82

Leary, M.R., Schreindorfer, L.S., and Haupt, A.L. (1995). The role of low self-esteem in emotional and behavioral problems: Why is low self-esteem dysfunctional? Journal of Social and Clinical Psychology, 14(3): 297-314

Livingstone, S. (2005). Audiences and publics: When cultural engagement matters for the public sphere. Portland, OR: Intellect. 
McDool, E., Powell, P., Roberts, J., \& Taylor, K. (2016). Social media use and children's wellbeing.

Ryan, R.M., and Deci, E.L. (2001). On happiness and human potentials: A review of research on hedonic and eudaimonic well-being. Annual Review of Psychology, 52(1): 141-166.

Sahin, C. (2018). Social media addiction scale-student form: The reliability and validity study. Turkish Online Journal of Educational Technology, 17(1): 169-182.

Seligman, M. (2011) Positive emotion, Engagement, Relationships, Meaning and Accomplishment, Optimism, Physical Activity, Nutrition and Sleep. South Australian Health and Medical Research Institute, The Wellbeing and Resilience Centre

Shaheen, M.A. (2008). Use of social networks and information seeking behavior of students during political crises in Pakistan: A case study. The International Information \& Library Review, 40(3): 142-147.

Sheldon, P., \& Bryant, K. (2016). Instagram: Motives for its use and relationship to narcissism and contextual age. Computers in human Behavior, 58, 89-97.

Shirase, R. (2012). The impact of social networking sites on personal lives of the people in Pune \& neighborhood. International Journal of Scientific \& Engineering Research, 3(9):1-12.

Stec, C. (2015). Social media definitions: The ultimate glossary of terms you should know. Hubspot.

Tariq, K., Tariq, R., Ayesha, Hussain, A., \& Shahid, M. (2019). Effects of smartphone usage on psychological wellbeing of school going children in Lahore, Pakistan. Journal of the Pakistan Medical Association (JPMA), 69(7):

Vannucci, A., \& Ohannessian, C.M. (2019). Social media use subgroups differentially predict psychosocial well-being during early adolescence. Journal of youth and adolescence, 48(8), 1469-1493.

Weinstein, E. (2018). The social media see-saw: Positive and negative influences on adolescents' affective well-being. New Media \& Society, 20(10):3597-3623. 